\title{
Efektivitas Sari Buah Lemon (Citrus limon (L.) Burm. f. sebagai Khelating Agent Logam Berat Tembaga
}

Novena Yety Lindawati, Juni Nofitasari*

Program Studi Farmasi, Sekolah Tinggi Ilmu Kesehatan Nasional, Sukoharjo, Indonesia

*Corresponding author: juni.nofita18@gmail.com

Submitted: 30 Mei 2020

Accepted: 11 November 2020

Published: 27 April 2021

\begin{abstract}
Background: Lemon (Citrus limon (L.) Burm. $F$ is a fruit that contains citric acid. Citric acid has the ability to bind heavy metals, one of which is copper heavy metals. Objective: The purpose of this study was to determine the effectiveness of lemon juice in reducing copper heavy metals. Phytochemical screening test was carried out to determine the content of secondary metabolites contained in lemon juice. Methods: Determination of the reduction in copper heavy metal levels was carried out by squeezing lemon added 10 ppm simulated copper metal which was read by the Atomic Absorption Spectrophotometer (AAS) method with a wavelength of $324.8 \mathrm{~nm}$. Determination of the reduction in copper metal was carried out using a series of lemon juice concentrations of 10,20,30,40,50, 60 and 70\%. Results: The results showed that lemon juice (Citrus limon $(L$. Burm. F. Contains metabolites in the form of citric acid, alkaloids, saponins, and steroids. The average value of reduction in copper metal levels after administration of lemon juice $10 \%$ concentration is $0.69( \pm 0.42 \%), 20 \%$ concentration of $1.80( \pm 0.42 \%), 30 \%$ concentration of $11.85( \pm 1.28 \%), 40 \%$ concentration of $33.57( \pm 0.33 \%)$, $50 \%$ concentration was $49.92( \pm 0.86 \%), 60 \%$ concentration was $54.14( \pm 0.69 \%)$ and $70 \%$ concentration was $64.89( \pm 0.30 \%)$. Conclusion: Effectiveness of lemon juice concentration which was able to reduce copper levels by $50 \%$ (EC50) was $55.88 \%$.
\end{abstract}

Keywords: lemon juice, EC50 value, copper metal reduction, AAS method

\begin{abstract}
Abstrak
Pendahuluan: Lemon (Citrus limon (L.) Burm. F merupakan salah satu buah yang mengandung asam sitrat. Asam Sitrat memiliki kemampuan mengikat logam berat, salah satunya logam berat tembaga. Tujuan: Tujuan dari penelitian ini adalah mengetahui efektivitas sari buah lemon dalam menurunkan logam berat tembaga. Uji Skrining fitokimia dilakukan untuk mengetahui kandungan metabolit sekunder yang terdapat dalam sari buah lemon. Metode: Penentuan penurunan kadar logam berat tembaga dilakukan dengan cara perasan buah lemon ditambahkan logam simulasi tembaga $10 \mathrm{ppm}$ yang dibaca dengan metode Spektrofotometer Serapan Atom (AAS) dengan panjang gelombang $324,8 \mathrm{~nm}$. Penentuan penurunan logam tembaga dilakukan dengan menggunakan seri konsentrasi sari buah lemon sebesar 10, 20, 30, 40, 50, 60 dan 70\%. Hasil: Hasil penelitian menunjukkan bahwa sari buah lemon (Citrus limon (L.) Burm. f. mengandung metabolit berupa asam sitrat, alkaloid, saponin, dan steroid. Nilai rata-rata penurunan kadar logam tembaga setelah pemberian sari buah lemon kosentrasi $10 \%$ sebesar $0,69( \pm 0,42 \%)$, konsentrasi $20 \%$ sebesar $1,80( \pm 0,42 \%)$, konsentrasi $30 \%$ sebesar 11,85 $( \pm 1,28 \%)$, konsentrasi $40 \%$ sebesar 33,57 $( \pm 0,33 \%)$, konsentrasi $50 \%$ sebesar 49,92 ( $\pm 0,86 \%)$, konsentrasi $60 \%$ sebesar 54,14 $( \pm 0,69 \%)$ dan konsentrasi $70 \%$ sebesar $64,89( \pm 0,30 \%)$. Kesimpulan: Nilai efektivitas konsentrasi sari buah lemon yang mampu menurunkan kadar tembaga sebesar $50 \%\left(\mathrm{EC}_{50}\right)$ adalah $55,88 \%$.
\end{abstract}

Kata kunci: sari buah lemon, nilai $\mathrm{EC}_{50}$, Penurunan logam tembaga, metode AAS 


\section{PENDAHULUAN}

Keberadaan logam berat sangat berbahaya bila kadar yang terlarut dalam tubuh manusia cukup tinggi. Logam berat akan tertimbun di dalam jaringan terutama hati dan ginjal. Logam berat tersebut dapat masuk dalam tubuh organisme melalui permukaan tubuh dan rantai makanan (Nurvita dkk., 2015).

Salah satu logam penyebab kerusakan hati yaitu tembaga $(\mathrm{Cu})$. Tembaga merupakan suatu logam esensial yang diperlukan oleh tubuh. Kandungan $\mathrm{Cu}$ dalam air minum yang diperbolehkan adalah $2 \mathrm{mg} / \mathrm{L}$ (Kuntum, 2014).

Bahan alam yang bersifat chelating agent adalah jeruk lemon. Kandungan jeruk lemon yaitu asam sitrat. Asam sitrat dapat membentuk senyawa kompleks dengan logam karena memiliki gugus fungsional $\mathrm{COOH}$ dan $-\mathrm{OH}$ (Solihah dkk., 2016), sehingga asam sitrat yang terkandung dalam buah jeruk lemon dapat digunakan untuk menurunkan kadar logam tembaga (Nurvita dkk., 2015).

Buah lemon mengandung senyawa lain selain asam sitrat yang dapat mengikat logam, salah satunya yaitu flavonoid yang berfungsi sebagai agen pengikat logam berat. Flavonoid dapat mentransfer elektron atau atom hidrogennya ke senyawa radikal bebas untuk dilakukan pengikat pada logam berat (Destria dkk., 2019).

Penelitian sebelumnya yang dilakukan oleh Hartika (2018) menunjukkan bahwa air perasan buah lemon dapat menurunkan logam Cd. Penelitian yang dilakukan oleh Harisman (2017), menunjukkan penambahan air perasan buah lemon dapat menurunkan logam $\mathrm{Pb}$. Perendaman dengan 100\% air perasan buah lemon selama 60 menit efektif untuk menurunkan kadar logam $\mathrm{Pb}$ pada ikan nila hitam sebesar $1,54 \mathrm{mg} / \mathrm{Kg}$ dengan besaran nilai penurunannya yaitu $82,80 \%$.

Penelitian buah lemon sebagai pengikat logam yang membentuk kompleks logam $\mathrm{Cu}$ belum dilaporkan, sehingga mendorong untuk dilakukannya penelitian.

\section{BAHAN DAN METODE}

\section{Bahan}

Bahan-bahan yang dibutuhkan dalam penelitian ini adalah Buah lemon masih segar dan matang serta memiliki panjang diameter $5-8 \mathrm{~cm}$ dengan bobot 50 $80 \mathrm{gr}$ buahnya berwarna kuning terang, yang diambil di salah satu mall di solo, aquabides (PT. Eka Pharmindo), $\mathrm{HCl}$ pekat, serbuk $\mathrm{Mg}$, gelatin $0,5 \%$,
$\mathrm{CuSO}_{4} .5 \mathrm{H}_{2} \mathrm{O}, \mathrm{H}_{2} \mathrm{SO}_{4} 2 \mathrm{~N}$, Mayer, Wagner, Dragendrof, $\mathrm{HCl} 1 \mathrm{~N}$, Lieberman Burchard, $\mathrm{H}_{2} \mathrm{SO}_{4}$ pekat, perak nitrat (Merck), kloroform (gradien grate $\geq 99,7 \%$ Emsure).

Alat

Alat yang digunakan adalah Spektrofotometri Serapan Atom (Thermo Scientific iCE-3500 GFZ), labu ukur 100,0 mL (Pyrex), corong pisah, klem statif, neraca analitik (Ohaus, EP214), alat stirrer magnetik, alat-alat gelas.

Metode

\section{Determinasi sampel}

Determinasi bertujuan untuk memastikan keaslian sampel yang digunakan dalam penelitian. Hasil determinasi menunjukkan bahwa tanaman yang diambil dari Kemuning, Karanganyar tersebut adalah tanaman lemon. Lemon dengan Spesies (Citrus limon (L.) Burm. f. dengan famili Rutaceae.

\section{Uji Skrining ftokimia \\ Uji flavonoid}

Filtrat ditambahkan $\mathrm{HCl}$ pekat dan logam Mg. Jika positif flavonoid ditunjukkan dengan perubahan warna kuning tua menjadi orange (Khotimah, 2016).

\section{Uji tannin}

Larutan filtrat ditambahkan gelatin $0,5 \%$. Hasil positif ditunjukkan dengan terbentuknya endapan coklat (Mabruroh, 2015).

\section{Uji alkaloid}

Filtrat dimasukkan kedalam tabung reaksi lalu ditambahkan 2 tetes $\mathrm{H}_{2} \mathrm{SO}_{4} 2 \mathrm{~N}$, kemudian dikocok hingga tercampur, kemudian dituangkan di plat tetes dan ditetesi pereaksi Mayer dengan melihat endapan putih, pereaksi Wagner dengan melihat endapan coklat, dan pereaksi Dragendrof dengan melihat endapan jingga (Erviani dkk., 2019).

\section{Uji saponin}

Filtrat ditambahkan air, dikocok, setelah dikocok tambahkan $\mathrm{HCl} 1 \mathrm{~N}$. Jika positif saponin terbentuk busa yang stabil (Wijaya dkk., 2014).

\section{Uji steroid triterpenoid}

Filtrat ditetesi pada 2 bagian plat tetes 1 bagian ditambahkan dengan pereaksi Lieberman Burchard jika terbentuk warna violet hasil ini menunjukkan positif untuk terpenoid, terbentuk warna biru menunjukkan positif steroid (Faskalia \& Wibowo, 2014).

\section{Uji asam sitrat}

Pertama, filtrat dipanaskan dengan asam sulfat pekat hasil positif berupa larutan warna menjadi lebih gelap (Puspadewi dkk., 2017). Lau yang kedua, filtrat 
direaksikan dengan $\left(\mathrm{AgNO}_{3}\right)$, hasil positif endapan putih (Puspadewi dkk., 2017).

Uji kuantitatif untuk memastikan keberadaan logam di dalam sampel

Seri konsentrasi perasan lemon 10, 20, 30, 40, 50, 60 , dan $70 \%$. Sari buah lemon masing-masing konsentrasi di buat dengan cara 10, 20, 30, 40, 50, 60 dan $70 \mathrm{~mL}$. Buah lemon segar dicuci, dipotong menjadi 3 bagian dimasukkan ke dalam wadah, disaring di ambil sarinya dengan cara air perasan lemon di masukkan kedalam labu ukur volume $100 \mathrm{~mL}$ tambahkan aquabides hingga volume $100 \mathrm{~mL}$, kemudian identifikasi menggunakan spektrofotometer serapan atom.

Pembuatan larutan baku induk logam $\mathrm{Cu} 1000$ ppm

Ditimbang 0,3929 gram $\mathrm{CuSO}_{4} .5 \mathrm{H}_{2} \mathrm{O}$ kemudian dilarutkan dengan aquabides hingga volume larutan $100 \mathrm{~mL}$.

\section{Pembuatan larutan baku induk logam $\mathrm{Cu} 10$ ppm}

Pipet $1 \mathrm{~mL}$ larutan baku induk $\mathrm{Cu} 1000$ ppm, masukkan dalam labu ukur volume 100,0 mL selanjutnya ditambah aquabides hingga volume $100 \mathrm{~mL}$.

\section{Uji penurunan logam tembaga}

Seri konsentrasi sari lemon 10, 20, 30, 40, 50, 60 $70 \%$ dibuat dengan cara melarutkan air perasan lemon $10,20,30,40,50,60$ dan $70 \mathrm{~mL}$ air perasan lemon dengan aquabides, selanjutnya di saring, masukkan dalam labu ukur volume $100,0 \mathrm{~mL}$, dan ditambahkan limbah simulasi logam $\mathrm{Cu}$ dengan konsentrasi 1000 ppm sebanyak $1 \mathrm{~mL}$, ditambahkan aquabides sampai volume $100 \mathrm{~mL}$. Campuran diaduk menggunakan stirer magnetik selama 60 menit. Campuran masukkan ke dalam corong pisah dan ditambah $10 \mathrm{~mL}$ kloroform penambahan kloroform bertujuan untuk memisahkan antara fase air dan fase kloroform, kemudian digojog selama 10 menit. Larutan tersebut didiamkan hingga terbentuk 2 fase. Fase air dianalisis. Fraksinasi dilakukan 3 kali. Fase air yang diperoleh selanjutnya dianalisis dengan Spektrofotometri Serapan Atom untuk menentukan konsentrasi logam $\mathrm{Cu}$ sisa dalam larutan. Pengujian dilakukan replikasi sebanyak 3 kali.

\section{Analisis data penelitian}

Pengukuran penurunan kadar dilakukan menggunakan Spektrofotometer Serapan Atom panjang gelombang $\mathrm{Cu} 324 \mathrm{~nm}$. Persen penurunan logam $\mathrm{Cu}$ diperoleh menggunakan rumus:

$\%$ Penurunan $=$

(Konsentrasi awal - Konsentrasi akhir) X 100\%

Konsentrasi awal

(Anggraini dkk., 2014)

Nilai $\mathrm{EC}_{50}$ merupakan konsentrasi suatu metabolit yang diperlukan untuk menurunkan kadar logam tembaga sebanyak 50\% dari kadar total logam awal.

Presisi diperoleh dari data rata-rata penurunan logam berat $\mathrm{Cu}$ yang masing-masing dilakukan 3 kali replikasi $(\mathrm{n}=3)$. Persen presisi dari nilai koefisien variasi. Nilai \% KV kecil maka data yang diperoleh baik. Ketentuan nilai $\mathrm{KV}$ adalah kurang dari $2 \%$ (Harmita, 2004).

\section{HASIL DAN PEMBAHASAN}

Penelitian yang dilakukan bertujuan mengetahui kemampuan sari buah lemon dalam menurunkan logam berat tembaga dengan metode Spektrofotometri Serapan Atom. Hasil determinasi menunjukkan bahwa tanaman yang diambil dari Kemuning, Karanganyar tersebut adalah tanaman lemon.

Uji skrining fitokimia untuk mengetahui kandungan metabolit sekunder yang terdapat dalam sari buah lemon, maka dilakukan skrining fitokimia yang terkandung dalam buah lemon yang dapat mengikat kadar logam tembaga. Penelitian ini menggunakan sampel lemon karena mempunyai kandungan asam sitrat.

Hasil dari Tabel 1 uji skrining fitokimia didapatkan hasil senyawa yang terkandung dalam buah lemon yaitu asam sitrat, alkaloid, flavonoid, fenolik, saponin, dan steroid. Kandungan dalam buah lemon yang mampu mengikat logam $\mathrm{Cu}$ adalah asam sitrat dan flavonoid. 
Tabel 1. Hasil uji kandungan fitokimia pada perasan buah lemon

\begin{tabular}{|c|c|c|c|c|}
\hline Uji Senyawa & Reagen & Teoritis & Hasil & Keterangan \\
\hline \multirow[t]{2}{*}{ Asam sitrat } & Asam sulfat pekat & Warna lebih gelap & Warna lebih gelap & Positif \\
\hline & Perak nitrat & Endapan putih & Endapan putih & Positif \\
\hline Flavonoid & $\begin{array}{l}\mathrm{HCl} \text { Pekat dan } \\
\text { Serbuk Mg }\end{array}$ & Orange & Orange & Positif \\
\hline \multirow[t]{3}{*}{ Alkaloid } & $\begin{array}{l}\text { Asam sulfat } 2 \mathrm{~N}+ \\
\text { Mayer }\end{array}$ & Endapan putih & Endapan putih & Positif \\
\hline & $\begin{array}{l}\text { Asam sulfat } 2 \mathrm{~N}+ \\
\text { Wagner }\end{array}$ & Endapan coklat & Endapan coklat & Positif \\
\hline & $\begin{array}{l}\text { Asam sulfat } 2 \mathrm{~N}+ \\
\text { Dragondroff }\end{array}$ & Endapan jingga & Endapan jingga & Positif \\
\hline Tanin & Gelatin $0,5 \%$ & Endapan coklat & $\begin{array}{l}\text { Tidak terdapat } \\
\text { endapan coklat }\end{array}$ & Negatif \\
\hline Saponin & $\begin{array}{c}\text { Air dikocok } 1 \text { menit } \\
+\mathrm{HCl} 1 \mathrm{~N}\end{array}$ & Busa stabil & Busa stabil & Positif \\
\hline $\begin{array}{l}\text { Steroid/Triterpe } \\
\text { noid }\end{array}$ & Liberman burchard & $\begin{array}{l}\text { Merah/violet untuk } \\
\text { triterpenoid } \\
\text { Hijau/biru untuk } \\
\text { steroid }\end{array}$ & Biru & $\begin{array}{l}\text { Positif steroid, } \\
\text { negatif } \\
\text { triterpenoid }\end{array}$ \\
\hline
\end{tabular}

\section{Uji Kuantitatif keberadaan logam dalam sampel}

Uji kuantitatif ini bertujuan untuk mengetahui keberadaan logam tembaga pada perasan buah lemon yang akan digunakan untuk penelitian. Buah lemon jika mengandung logam tembaga dapat mempengaruhi kadar logam mula-mula sebelum di tambahkan logam. Hasil dari uji kuantitatif pada sampel sari buah lemon yang digunakan mengandung logam tembaga konsentrasi $10 \%$ kandungan logam dalam sampel $0,0374 \%$, konsentrasi $20 \%$ kandungan logam dalam sampel $0,0662 \%$, konsentrasi $30 \%$ kandungan logam dalam sampel $0,6258 \%$, konsentrasi $40 \%$ kandungan logam dalam sampel $0,8604 \%$, konsentrasi $50 \%$ kandungan logam dalam sampel $0,6103 \%$, konsentrasi $60 \%$ kandungan logam dalam sampel 0,2508\%, konsentrasi $70 \%$ kandungan logam dalam sampel $0,1743 \%$. Kandungan logam tembaga ini akan diperhitungkan dalam presentse penurunan kadar logam tembaga.

\section{Uji penurunan logam tembaga}

Pengujian buah lemon terhadap penurunan kadar logam tembaga seri konsentrasi buah lemon 10, 20, 30, 40, 50, 60 dan 70\% yang telah ditambahkan logam tembaga $10 \mathrm{ppm}$. Proses pengikat logam dilakukan 60 menit untuk memaksimalkan penurunan kadar logam tembaga. Proses pemisahan kompleks dengan sisa logam tembaga dilakukan melalui metode ekstraksi. Metode ekstraksi dilakukan pada lemon yang sudah ditambahkan dengan logam. Ekstrasi dilakukan menggunakan pelarut organik kloroform penambahan kloroform bertujuan untuk memisahkan sisa logam tembaga dengan kompleks. Pelarut tersebut mempunyai sifat non polar dibanding dengan air dan tidak bercampur dengan air. Senyawa yang masuk dalam fase kloroform yaitu senyawa non polar sedangkan senyawa yang masuk dalam air yaitu senyawa polar. Sifat kepolaran akan sangat berpengaruh terhadap kemudahan kompleks yang terbentuk terdistribusi ke fase organik, sedangkan sifatnya yang tidak bercampur dengan air akan memudahkan dalam proses pemisahan kompleks tersebut dari campurannya dalam fase air (Anggraini dkk., 2014). Senyawa yang masuk dalam fase air yaitu flavonid sedangkan senyawa yang masuk dalam fase kloroform alkaloid. Fase air yang diperoleh selanjutnya di analisis Spektrofotometer Serapan Atom.

Hasil dari Tabel 2 sari buah lemon semakin tinggi konsentrasi perasan buah lemon semakin besar penurunan logam tembaga. Hal ini berarti senyawa organik yang terdapat pada sari lemon dapat mengikat logam tembaga. Penurunan logam tembaga kosentrasi $10 \%$ sebesar $0,69( \pm 0,42 \%)$, konsentrasi $20 \%$ sebesar 1,80 ( \pm 0,42\%), konsentrasi $30 \%$ sebesar 11,85 $( \pm 1,28 \%)$, konsentrasi $40 \%$ sebesar 33,57 ( $\pm 0,33 \%)$, konsentrasi $50 \%$ sebesar 49,92 $( \pm 0,86 \%)$, konsentrasi $60 \%$ sebesar $54,14( \pm 0,69 \%)$ dan konsentrasi $70 \%$ sebesar 64,89 $( \pm 0,30 \%)$. Nilai $\mathrm{EC}_{50}$ yang diperoleh dari penelitian pengembangan mengenai pemanfaatan perasan buah lemon sebagai khelating agent logam berat $\mathrm{Cu}$ yaitu $55,88 \%$. 
Tabel 2. Rata-rata penurunan kadar tembaga dari setiap konsentrasi

\begin{tabular}{ccccc}
\hline konsentrasi sampel & Penurunan kadar logam tembaga & $\% \mathrm{KV}$ & Persamaan regresi linear & EC $_{50}$ \\
\hline $10 \%$ & $0,69 \%$ & 0,42 & & \\
$20 \%$ & $1,80 \%$ & 0,42 & $\mathrm{y}=1,1975 \mathrm{x}+-16,9157$ & $55,88 \%$ \\
$30 \%$ & $11,85 \%$ & 1,28 & & \\
$40 \%$ & $33,57 \%$ & 0,33 & \\
$50 \%$ & $49,92 \%$ & 0,86 & \\
$60 \%$ & $54,14 \%$ & 0,69 & \\
$70 \%$ & $64,89 \%$ & 0,30 & \\
\hline
\end{tabular}

Senyawa organik dalam sari buah lemon yang berperan dalam mengikat logam menurut penelitian yang sebelumnya adalah senyawa asam sitrat dan flavonoid. Asam sitrat mempunyai gugus fungsional karboksil - $\mathrm{COOH}$, mengalami deprotonisasi, sehingga mempunyai peluang membentuk kompleks dengan ion logam yang disebut khelasi (Gambar 1).

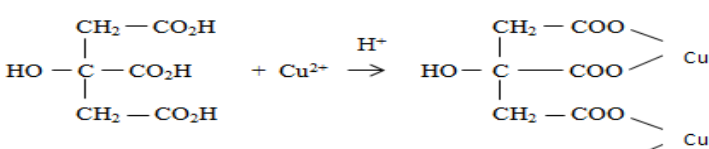

$$
\begin{aligned}
& \mathrm{HO}-{\underset{\mathrm{CH}}{\mathrm{C}}-\mathrm{COO}}_{\mathrm{CH}_{2}-\mathrm{COO}}^{\mathrm{C}}-\mathrm{Cu}
\end{aligned}
$$

Gambar 1. Reaksi asam sitrat dengan logam $\mathrm{Cu}$ (Wandya, 2018)

Senyawa flavonoid dapat mentransfer elektron atau atom hidrogennya untuk dilakukan pengikatan dengan logam berat. Senyawa organik yang dapat berikatan dengan ion logam membentuk kompleks dengan struktur seperti cincin yang disebut dengan kelat. (Gambar 2). Reaksi dari pengikatan logam berat oleh flavonoid sebagai berikut:

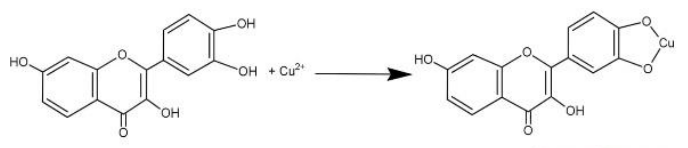

Gambar 2. Reaksi flavonoid dengan $\operatorname{logam} \mathrm{Cu}$ (Widyawati, 2007)

Koefisien variasi (\%KV) ditetapkan untuk mengetahui kedekatan hasil analisis satu dengan hasil analisis lain dari suatu seri pengukuran secara berulang-ulang dari sampel yang homogen, kriteria nilai $\mathrm{KV}$ yang baik adalah kurang dari $2 \%$. Nilai KV yang diperoleh dari masing-masing konsentrasi kurang dari $2 \%$. Hasil tersebut menunjukkan bahwa data diperoleh memenuhi persyaratan yaitu kurang dari $2 \%$ (Harmita, 2004), maka dapat dikatakan data replikasi 1, replikasi 2, dan replikasi 3 tidak berbeda jauh hal tersebut menunjukkan bahwa data diperoleh dengan tingkat ketelitian kerja yang baik.

\section{KESIMPULAN}

Sari lemon Citrus limon (L.) Burm. f. mampu menurunkan kadar logam berat tembaga $(\mathrm{Cu})$ dan memiliki nilai $\mathrm{EC}_{50}$ sebesar 55,88\%.

\section{DAFTAR PUSTAKA}

Anggraini, D. I., Sukirno \& Wulansari, A. D. (2014). Antidotum Logam Timbal $(\mathrm{Pb})$ secara In Vitro dengan Seduhan Air Teh Hijau. Jurnal Ilmiah Kesehatan; 6; 105-108.

Destria, M., Ari, W. \& Afghani, J. (2019). Senyawa Flavonoid dari Fraksi Diklorometana Buah Mangga Golek (Mangifera spp.) sebagai pengompleks $\mathrm{Fe}^{2+}$. Jurnal Kimia Khatulistiwa; 8; 17-25.

Erviani, E. A., Arif, R. A. \& Nurfahmiatunnisa. (2019). Analisis Rendemen dan Skrining Fitokimia Ekstrak Cacing Laut Eunice siciliensis. Jurnal Ilmu Alam dan Lingkungan; 10; 1-7.

Faskalia \& Wibowo, A. M. (2014). Skrining Fitokimia Uji Aktivitas Antioksidan dan Uji Sitotoksik Ekstrak Metanol pada Akar dan Kulit Batang Soma (Ploiarium alternifolium). Jurnal Kimia Khatulistiwa; 3; 1-6

Harisman, M. H. (2017). Efektivitas Air Perasan Buah Lemon (Citrus Limon) terhadap Penurunan Kadar Timbal $(\mathrm{Pb})$ Pada Daging Ikan Nila Hitam (Oreochromis nilaticus). Skripsi; Fakultas Farmasi Universitas Al-Ghifari, Bandung.

Harmita. (2004). Petunjuk Pelaksanaan Validasi Metode dan Cara Perhitungannya. Majalah Ilmu Kefarmasian; 1; 117-135.

Hartika, F. (2018). Pemanfaatan Air Perasan Jeruk Lemon (Citrus limon) terhadap Penurunan Kadar Kadmium pada Kerang Darah (Anadara Granosa L.) secara Spektrofotometri Serapan Atom. Skripsi; Fakultas Farmasi Universitas Sumatera Utara, Medan.

Khotimah, K. (2016). Skrining Fitokimia dan Identifikasi Metabolit Sekunder Senyawa 
Karpain pada Ekstrak Metanol Daun (Carica pubescens Lenne) \& K. Koch dengan LC/MS (Liquid Chromatograph-Tandem Mass Spectrometry). Skripsi; Fakultas Sains dan Teknologi Universitas Islam Negeri Maulana Ibrahim, Malang.

Kuntum, K. (2014). Analisis Kadar tembaga (Cu) dan Seng ( $\mathrm{Zn}$ ) dalam air Minuman Isi Ulang Kemasan Galon di Kecamatan Lima Kaum Kabupaten Tanah Datar. Jurnal Sainstek; 6; 116-123

Mabruroh I. A. (2015). Uji Aktivitas Antioksidan Ekstrak Tanin dari Daun Rumput Bambu (Lophatherum gracile Brongn) dan Identifikasinya. Skripsi; Fakultas Sains dan Teknologi Universitas Islam Negeri Maulana Malik Ibrahim, Malang.

Nurvita, S. N., Yunita \& Astorina, Nikie. (2015). Pengaruh Variasi Konsentrasi Air Jeruk Nipis (Citrus aurantifolia) Dalam Menurunkan Kadar Kadmium (Cd) Pada Daging Kerang Darah (Anadara granosa). Jurnal Kesehatan Masyarakat; 3; 807-818.
Puspadewi, R., Anugrah, R. \& Sabila, D. (2017). Kemampuan Aspergillus wentii dalam Menghasilkan Asam Sitrat. Jurnal Ilmiah Farmasi; 5; 15-20

Solihah, M., Rachmadiarti, F. \& Raharjo. (2016). Pemanfaatan Filtrat Asam Jawa (Tamarindus indica. $L)$ untuk menurunkan Kadar Timbal $(\mathrm{Pb})$ pada Ikan Bander Putih (Barbonymus gonionotus). Lentera Bi; 5; 133-138.

Wandya, T. U., (2018). Efektivitas Larutan Jeruk Nipis terhadap Penurunan Kadar Timbal $(\mathrm{Pb})$ pada Kerang Darah (Andara granosa) Tahun 2018. Skripsi; Fakultas Kesehatan Masyarakat Universitas Sumatera Utara, Medan.

Widyawati, W. (2007). Efek Ekstrak Daun Sambung Nyawa (Gynura procumbens (Lour)). Skripsi; Fakultas Matematika dan Ilmu Pengetahuan Alam Universitas Sebelas Maret, Surakarta.

Wijaya, P. D., Paendonga, E. J. \& Abidjulu, J. (2014), Skrining Fitokimia dan Uji Aktivitas Antioksidan dari Daun Nasi (phrynium capitatum) dengan Metode DPPH (1,1-difenil-2pikrilhidrazil). Jurnal MIPA UNSRAT ONLINE; 3; 11-15. 